\title{
TITLE:
}

\section{Beech cupules share endophytic fungi with leaves and twigs}

$\operatorname{AUTHOR}(\mathrm{S}):$

Tateno, Osamu; Hirose, Dai; Osono, Takashi;

Takeda, Hiroshi

\section{CITATION:}

Tateno, Osamu ...[et al]. Beech cupules share endophytic fungi with leaves and twigs. Mycoscience 2015, 56(3): 252-256

\section{ISSUE DATE:}

2015-05

URL:

http://hdl.handle.net/2433/201893

\section{RIGHT:}

(c) 2015. This manuscript version is made available under the CC-BY-NC-ND 4.0 license

http://creativecommons.org/licenses/by-nc-nd/4.0/; The full-text file will be made open to the public on 1 June 2016 in accordance with publisher's 'Terms and Conditions for Self-Archiving'.; この論文は出版社版でありません。引用の際に は出版社版をご確認ご利用ください。; This is not the published version. Please cite only the published version. 
1 Beech cupules share endophytic fungi with leaves and twigs

2

3 Osamu Tateno a, Dai Hirose b, Takashi Osono ${ }^{\text {c,* }}{ }^{\text {, Hiroshi Takeda }}{ }^{\mathrm{d}}$

4

5 a Graduate School of Agriculture, Kyoto University, Kyoto 606-8502, Japan

6 b College of Pharmacy, Nihon University, Funabashi, Chiba 274-8555, Japan

7 c Center for Ecological Research, Kyoto University, Otsu, Shiga 520-2113, Japan

8 d Faculty of Engineering, Doshisha University, Kyoto 610-0394, Japan

9

10 * Corresponding author. Tel.: +81 77549 8252; fax: +81 775498201.

11 E-mail address: tosono@ecology.kyoto-u.ac.jp (T. Osono)

12

13 Number of figures: 3

14 


\section{Abstract}

2

3 Endophytic mycobiota on leaves, twigs and cupules of Fagus crenata were

4 investigated using a culture-dependent method over a growing season to test the

5 hypothesis that endophytic fungi of cupule (a woody phyllome) share some

6 components of the endophytic fungal assemblages with both leaves and twigs. A

7 total of 14 fungal taxa were isolated, and the most frequent taxon was Phomopsis

8 sp., followed by Xylaria sp., Ascochyta fagi and Geniculosporium sp. The

9 compositions of fungal assemblages of leaf laminae and petioles were generally

10 relatively dissimilar to those of current and first year twigs when compared for

11 each sampling month, and those of cupules and cupule stalks were intermediate

12 between those of leaves and twigs. Permutational multivariate analysis of

13 variance confirmed that month and organ were significant factors of the variation

14 of the composition of endophytic fungal assemblages. Phomopsis sp., a common

15 twig endophyte, and $A$. fagi, a common leaf endophyte, were common in cupules 16 and cupule stalks. These results suggested that the endophytic fungal 17 assemblages of cupules shared component taxa with those of both leaves and 18 twigs.

20 Keyword: Endophyte $\cdot$ Fagus crenata $\cdot$ Leaf $\cdot$ rRNA gene sequence analysis • 21 Season 
1

2

3 Endophytic fungi include those that can colonize internal plant tissues at some

4 time in their life without causing apparent harm to their host (Sieber 2007).

5 Beech (Fagus spp.) is a dominant tree of cool temperate forests and has been

6 examined for endophytic fungi, with intensive efforts devoted to Japanese beech $F$.

7 crenata (Sahashi et al. 1999, 2000; Kaneko and Kakishima 2001; Osono 2002;

8 Kaneko et al. 2003; Osono and Mori 2003; Kaneko and Kaneko 2004; Fukasawa et

9 al. 2009; Hashizume et al. 2010), European beech F. sylvatica (Sieber and hypothesis.

\section{Materials and methods}


2

3 Samples were collected in Ashiu Experimental Forest of Kyoto University

$4 \quad\left(35^{\circ} 18^{\prime} \mathrm{N}\right.$ and $\left.135^{\circ} 43^{\prime} \mathrm{E}\right)$, Kyoto, Japan. Details of the study site were described in

5 Osono et al. (2011). In the study site, mass flowering of $F$. crenata and mass

6 production of cupules were observed in 2005, whereas only a few individual trees

7 flowered in 2006. We selected a mature tree (height $16 \mathrm{~m}$ ) that flowered in 2006,

8 and shoots with flowers were harvested from the canopy at approx. 5-8 $\mathrm{m}$ height

9 in Jun, Aug and Oct 2006. Ten shoots carrying current-year leaves, maturing cupules, a current-year twig and a one-year twig (Fig. 1) were arbitrarily selected

11 from the canopy and harvested on each sampling date. Healthy-looking shoots without obvious faunal and/or microbial attacks were selected. The samples were placed in paper bags and taken to the laboratory.

One leaf, one cupule, two current-year twigs (1 cm in length) and two first-year twigs ( $1 \mathrm{~cm}$ in length) were taken from each shoot. The leaf was divided into lamina and petiole, and four leaf disks were punched from the lamina with a sterile cork borer $(5.5 \mathrm{~mm}$ in diameter) from the central part of leaves, avoiding the primary vein. The cupule was cut into four equivalent pieces and one stalk. Thus, a total of 40 disks of leaf lamina, 10 petioles, 40 pieces of cupules, 10 cupule stalks, 20 current-year twigs and 20 first-year twigs were prepared on each sampling date and used for the isolation of fungi.

\subsection{Fungal isolation}


2 A surface sterilization method by Osono et al. (2008) was used for the isolation of

3 fungi from beech organs. Fungal isolation was carried out within 24 hours of

4 sampling. The plant organ samples were submerged in $70 \%$ ethanol (v/v) for $1 \mathrm{~min}$

5 to wet the surface, then surface-disinfected for $30 \mathrm{~s}$ in a solution of $15 \%$ hydrogen

6 peroxide, and submerged again for $1 \mathrm{~min}$ in $70 \%$ ethanol. The samples were

$7 \quad$ rinsed with sterile distilled water, transferred to sterile filter paper in Petri dishes

8 (9 $\mathrm{cm}$ in diameter), and dried for $24 \mathrm{~h}$ to suppress vigorous bacterial growth after

9 plating (Widden and Parkinson 1973). The leaf disks or pieces from cupules and 10 twigs were placed in 9-cm Petri dishes containing malt extract agar (malt extract

$112 \% \mathrm{w} / \mathrm{v}$, agar 2\%; Nacalai tesque, Kyoto, Japan), with two disks/pieces per plate.

12 Plates were incubated at $20^{\circ} \mathrm{C}$ in the dark and observed at 1,4 and 8 weeks after

13 surface sterilization. Identification was primarily based on micromorphological 14 observations, with reference to Gams (2007). Some isolates were then used for

15 molecular analysis as described below. The frequency of an individual taxon was 16 calculated as the percentage of incidences based on the number of plant organs 17 with the taxon relative to the total number of the organ, for each sampling date. 18 Taxa with low frequencies were specifically discussed only if their occurrence was 19 of special interest.

2.3. DNA analysis

23 Twenty-two isolates of Phomopsis sp., Xylaria sp. and Geniculosporium sp. were 
1 used for DNA analysis. Thirteen isolates of Phomopsis sp. included seven from

2 cupules, one from cupule stalk, two from twigs and three from lamina. Seven

3 isolates of Xylaria sp. included four from cupules, two from cupule stalks and one

4 from leaf lamina. Two isolates of Geniculosporium sp. included one from cupule

5 and one from cupule stalk. Before DNA extraction, the isolates were subcultured

6 in $2 \%$ malt extract liquid medium. The DNA was extracted from small quantities

7 of mycelia using DNeasy Plant mini kit (Qiagen, Hilden, Germany) according to

8 the manufacturer's instructions. Polymerase chain reactions (PCR) were

9 performed using a Quick Taq HS DyeMix (Toyobo, Osaka, Japan). Each PCR

10 reaction contained a $50 \mu \mathrm{l}$ mixture $(21 \mu \mathrm{l}$ distilled water, $25 \mu \mathrm{l}$ master mix, $3 \mu \mathrm{l}$ ca.

$110.5 \mathrm{ng} / \mathrm{\mu l}$ template DNA and $0.5 \mu \mathrm{l}$ each primer (final, $0.25 \mu \mathrm{M}$ )). The primer pair

12 ITS1f (Gardes and Bruns 1993) / LR3 (Vilgalys and Hester 1990) was used to

13 obtain the ITS2 and the D1-D2 domain of the 28S rRNA. Each DNA fragment was

14 amplified using a PCR thermal cycler (DNA Engine, Bio-Rad Laboratories,

15 Hercules, USA) using the following thermal cycling schedule: the first cycle

16 consisted of $2 \mathrm{~min}$ at $94{ }^{\circ} \mathrm{C}$, followed by 35 cycles of $30 \mathrm{~s}$ at $94{ }^{\circ} \mathrm{C}, 30 \mathrm{~s}$ at $50{ }^{\circ} \mathrm{C}$ for

17 annealing, $1 \mathrm{~min}$ at $68{ }^{\circ} \mathrm{C}$, and a final cycle of $10 \mathrm{~min}$ at $68{ }^{\circ} \mathrm{C}$. The PCR products

18 were purified using a QiAquick PCR Purification Kit (Quiagen). The purified PCR

19 products were sequenced by Macrogen Japan Corp. (Tokyo, Japan). The sequences

20 determined in this study were deposited in the DNA Data Bank of Japan (DDBJ)

21 (AB915934-AB915946, AB918138-AB918140, AB918142-AB918147). The ITS2

22 and 28S rRNA gene sequences were compared using MEGA5 (Tamura et al. 2011)

23 to determine the sequences identity. All positions containing gaps and missing 
1 data eliminated from the sequences, resulting in 884, 875 and 887 bases for

2 Phomopsis sp., Xylaria sp. and Geniculosporium sp., respectively, for the

3 comparisons. The sequences were then compared with the GenBank database

4 using BLAST (Altschul et al. 1997).

5

$6 \quad$ 2.4. Statistical analysis

8 We prepared a datasheet of endophytic fungal assemblages indicating the

9 frequency of 14 endophytic fungal taxa on 18 samples (six organs each for three months). To compare the composition of endophytic fungal assemblages of organs

11 within the shoot, we used nonmetric multidimensional scaling (NMDS) with the 12 Bray-Curtis distance metric. The NMDS analysis was carried out with the 13 metaNDS function with default settings of the vegan package (Oksanen et al. 14 2011) in the $\mathrm{R}$ version 3.0.2 for Mac (http://www.r-project.org). We then assessed 15 the effect of month and organ on endophytic fungal assemblage, by analyzing the average Bray-Curtis dissimilarity matrices in permutational multivariate

17 analysis of variance (PERMANOVA, Anderson 2001) with the adonis function of 18 the $\mathrm{R}$ vegan package. Effects of month and organ on the frequency of four major 19 fungal taxa (Phomopsis sp., Xylaria sp., A. fagi and Geniculosporium sp.) were 20 analyzed with generalized linear models (GLMs) with a Poisson distribution. The 21 GLMs were performed with the glm function and with the glht function of the R 22 multcomp package for multiple comparisons with Tukey's test. 


\section{$1 \quad 3$. Results and discussion}

2

3 A total of 14 fungal taxa were isolated from organs of $F$. crenata. The most

4 frequent taxon was Phomopsis sp., followed by Xylaria sp., A. fagi and

$5 \quad$ Geniculosporium sp. Less frequent taxa included Epicoccum nigrum, Alternaria

6 spp., Chaetomium sp., Nigrospora sp., and six unidentified morphotaxa.

7 Phomopsis sp. and $A$. fagi have been encountered in several beech forests in

8 Japan as major endophytic fungi of twigs and leaves, respectively (Sahashi et al.

9 2000; Kaneko et al. 2003; Osono and Mori 2003; Hashizume et al. 2010). Xylaria sp. and Geniculosporium sp. are common Xylariaceous endophytes of leaves of

11 multiple tree species in cool temperate forests (Osono et al. 2013; Ikeda et al. 2014) and in tropical forests (Okane et al. 2008, 2012). Xylaria sp. also occurs in

13 beech twigs (Fukasawa et al. 2009, 2013). Fukasawa et al. (2012) reported

14 frequent occurrence of Xylaria sp., Phomopsis sp. and $A$. fagi during the initial 15 stages of cupule decomposition on the soil. In contrast, Dasyscyphella 16 longistipitata and $X$. carpophila, which frequently produce fruiting bodies on dead cupules (Hosoya et al. 2010; Fukasawa et al. 2012), were not isolated from living tissues of cupules, leaves, or twigs.

The rRNA sequences of isolates of Phomopsis sp., Xylaria sp., and

20 Geniculosporium sp. from different organs showed similarities between 99.7\%

21 and $100.0 \%$, between $99.8 \%$ and $100.0 \%$ and $99.9 \%$, respectively, indicating that

22 the respective isolates belonged to single fungal species and that these three 23 species had low organ specificity. Taxonomic assignment using BLAST searches 
1 demonstrated that the base sequences of Phomopsis sp. had affinities to those of $P$.

2 mali (AB665315), P. conorum (DQ116553), P. fukushii (JQ807469) and Diaporthe

3 eres (JQ807441) with query coverages of 100\% and max identities of $99 \%$ for all

4 accessions. Xylaria sp. and Geniculosporium sp. were identical to ubiquitous foliar

5 endophytes of multiple tree species in the study site (Osono et al. 2013),

6 suggesting that these species had low levels of not only organ specificity but also

7 host specificity.

8 The NMDS ordination showed differences in the endophytic fungal

9 assemblages with respect to month and organ (Fig. 2). The compositions of fungal

10 assemblages of leaves (leaf laminae and petioles) were generally dissimilar to

11 those of twigs (current and first year twigs) when compared for each sampling

12 month, and those of cupules and cupule stalks were intermediate between those of

13 leaves and twigs. Permutational multivariate analysis of variance confirmed that

14 month and organ were significant factors of variation of the composition of

15 endophytic fungal assemblages (month: d.f. $=2, F=6.04, P<0.001$; organ: d.f.=5,

$16 F=4.20, P<0.001)$. These differences in endophytic fungal assemblages with

17 respect to month and organ were chiefly attributed to the variations in the

18 frequency of major endophytic fungal taxa as described below. Previous studies

19 have already documented seasonal changes in endophytic fungal assemblages in

20 tree leaves (e.g., Hata et al. 1998; Sahashi et al. 1999; Osono 2008; Osono et al. $212009)$.

Figure 3 shows the frequencies of four major endophytic taxa. Phomopsis

23 sp. was significantly more frequent in cupules, cupule stalks and current and first 
1 year twigs than in leaf laminae and petioles, and more frequent in Aug than in

2 Jun or Oct. Xylaria sp. was more frequent in the order: cupule stalks $>$ first year

3 twigs $>$ cupules $>$ current year twigs $>$ leaf petioles $>$ leaf laminae, and increased

4 from Jun to Aug and to Oct. Ascochyta fagi was significantly more frequent in leaf

5 laminae and cupules than in leaf petioles and cupule stalks and in current and

6 first year twigs, and increased from Jun to Aug and to Oct. Geniculosporium sp.

7 was significantly more frequent in cupule stalks and leaf petioles than in current

8 and first year twigs, and more frequent in Jun and Oct than in Aug.

These results supported our hypothesis and indicated that the endophytic fungal assemblages of cupules shared features with those of both

11 leaves and twigs. One possible explanation is that cupules could serve as habitat and food suitable for the colonization of endophytic fungi associated with both

13 leaves and twigs because cupules as woody phyllomes not only share the origin

14 with leaves but also possess chemical similarities to twigs (Osono and Takeda

15 2001; Fukasawa et al. 2009, 2012). Another possibility is that cupules are located

16 between leaves and twigs within the shoot (Fig. 1) and therefore can readily be

17 infected by endophytic fungi of these organs, leading to the intermediate

18 composition of endophytic fungal assemblages. In this respect, it is noteworthy

19 that the frequency of $A$. fagi in cupules in June appeared higher than that in the

20 other organs, including leaf laminae (Fig. 3), suggesting the advanced colonization

21 of current year shoots by this fungal species through cupules in early months of

22 the growing season. Such facilitated colonization may lead to higher incidence of

23 A. fagi in fruiting beech shoots than in non-fruiting ones. Further studies are 
1 needed to test whether this hypothesis is applicable to other beech trees and tree

2 species.

3

4

\section{Acknowledgements}

6 We thank Dr. Y. Fukasawa and members of Ashiu Experimental Forest of Kyoto

7 University for help with fieldwork; and Dr. E. Nakajima for critical reading of the

8 manuscript. This study received partial financial support from the Ministry of

9 Education, Culture, Sports, Science, and Technology of Japan (MEXT) (No.

23770083) and Grants for Excellent Graduate Schools, MEXT, Japan (12-01) to

11 Kyoto University,

References

Altschul SF, Madden TL, Schaffer AA, Zhang JH, Zhang Z, Miller W, Lipman DJ, 1997. Gapped BLAST and PSI-BLAST: a new generation of protein database search programs. Nucleic Acids Research 25: 3389-3402; doi: 10.1093/nar/25.17.3389.

Anderson MJ, 2001. A new method for non-parametric multivariate analysis of variance. Austral Ecology 26: 32-46; doi: 10.1111/j.1442-9993.2001.01070.

Chapela IH, 1989. Fungi in healthy stems and branches of American beech and aspen: a comparative study. New Phytologist 113: 65-75; doi: 
Danti R, Sieber TN, Sanguineti G, 2002. Endophytic mycobiota in bark of European beech (Fagus sylvatica) in the Apennines. Mycological Research 106: 1343-1348; doi: 10.1017/S0953756202006779. 1067-1073; doi: 10.1007/s11284-009-0582-9. litter decomposition by fungal colonizers. Journal of Integrated Field Science 10: 1-6.

Fukasawa Y, Tateno O, Hagiwara Y, Hirose D, Osono T, 2012. Fungal succession and decomposition of beech cupule litter. Ecological Research 27: 735-743; doi: 10.1007/s11284-012-0947-3.

Gams W, 2007. Compendium of soil fungi, 2nd ed. IHW-Verlag \& Verlagsbuchhandlung, Eching. Molecular Ecology 21: 113-118.

Hashizume Y, Fukuda K, Sahashi N, 2010. Effects of summer temperature on fungal endophyte assemblages in Japanese beech (Fagus crenata) leaves in pure beech stands. Botany 88: 266-274; doi: 10.1139/B09-114.

Hata K, Futai K, Tsuda M, 1998. Seasonal and needle age-dependent changes of the endophytic mycobiota in Pinus thunbergii and Pinus densiflora 
needles. Canadian Journal of Botany 76: 245-250.

Hosoya T, Hirose D, Fujisaki M, Osono T, Kubono T, Tokumasu S, Kakishima M, 2010. Internal transcribed spacer haplotype diversity and their geographical distribution in Dasyscyphella longistipitata (Hyaloscyphaceae, Helotiales) occurring on Fagus crenata cupules in Japan. Mycoscience 51: 116-122.

Ikeda A, Matsuoka S, Masuya H, Mori AS, Hirose D, Osono T, 2014. Comparison of the diversity, composition, and host recurrence of xylariaceous endophytes in subtropical, cool temperate, and subboreal regions in Japan. Population Ecology 56:289-300; doi: 10.1007/s10144-013-0412-3.

Kaneko R, Kakishima M, 2001. Mycosphaerella buna sp. nov. with a Pseudocercospora anamorph isolated from the leaves of Japanese beech. Mycoscience 42: 59-66.

Kaneko R, Kakishima M, Tokumasu S, 2003. The seasonal occurrence of endophytic fungus, Mycosphaerella buna, in Japanese beech Fagus crenata. Mycoscience 44: 277-281.

Kaneko R, Kaneko S, 2004. The effect of bagging branches on levels of endophytic fungal infection in Japanese beech leaves. Forest Pathology 34: 65-78; doi: 10.1111/j.1439-0329.2004.00350.x.

Okane I, Srikitikulchai P, Tabuchi Y, Sivichai S, Nakagiri A, 2012. Recognition and characterization of four Thai xylariaceous fungi inhabiting various tropical foliages as endophytes by DNA sequences and host plant preference. Mycoscience 53: 122-132. 
1 Okane I, Srikitikulchai P, Toyama K, Læssøe T, Sivichai S, Hywel-Jones N,

Nakagiri A, Potacharoen W, Suzuki K, 2008. Study of endophytic Xylariaceae in Thailand: diversity and taxonomy inferred from rDNA sequence analyses with saprobes forming fruit bodies in the field. Mycoscience 49: 359-372.

Oksanen J, Blanchet FG, Kindt R, Legendre P, Minchin PR, O'Hara RB, Simpson GL, Solymos P, Stevens HMM, Wagner H, 2011. Package 'vegan' version 2.0-2. http://cran.r-project.org/web/packages/vegan/index.html, accessed 8 Jul 2014.

Osono T, 2002. Phyllosphere fungi on leaf litter of Fagus crenata: occurrence, colonization, and succession. Canadian Journal of Botany 80: 460-469.

Osono T, 2008. Endophytic and epiphytic phyllosphere fungi of Camellia japonica: seasonal and leaf age dependent variations. Mycologia 100: 387-391; doi: doi: 10.3852/07-110R1.

Osono T, Hobara S, Hishinuma T, Azuma JI, 2011. Selective lignin decomposition and nitrogen mineralization in forest litter colonized by Clitocybe sp. European Journal of Soil Biology 47: 114-121.

Osono T, Ishii Y, Hirose D, 2008. Fungal colonization and decomposition of Castanopsis sieboldii leaf litter in a subtropical forest. Ecological Research 23: 909-917; doi: 10.1007/ s11284-007-0455-z.

Osono T, Ishii Y, Takeda H, Seramethakun T, Khamyong S, To-Anun C, Hirose D, Tokumasu S, Kakishima M, 2009. Fungal succession and lignin decomposition on Shorea obtusa leaves in a tropical seasonal forest in 
northern Thailand. Fungal Diversity 36: 101-119.

2 Osono T, Mori A, 2003. Colonization of Japanese beech leaves by phyllosphere fungi. Mycoscience 44: 437-441. litter of Fagus crenata (in Japanese with English abstract). Applied Forest Science Kansai 8: 103-108.

Osono T, Tateno O, Masuya H, 2013. Diversity and ubiquity of xylariaceous

Osono T, Takeda H, 2001. Organic chemical and nutrient dynamics in decomposing beech leaf litter in relation to fungal ingrowth and succession during three year decomposition processes in a cool temperate deciduous forest in Japan. Ecological Research 16: 649-670; doi: 10.1046/j.1440-1703.2001.00426.x. endophytes in live and dead leaves of temperate forest trees. Mycoscience 54: $54-61$.

Sahashi N, Kubono T, Miyasawa Y, Ito S, 1999. Temporal variations in isolation frequency of endophytic fungi of Japanese beech. Canadian Journal of Botany 77: 197-202.

Sahashi N, Miyasawa Y, Kubono T, Ito S, 2000. Colonization of beech leaves by two endophytic fungi in northern Japan. Forest Pathology 30: 77-86; doi: 10.1046/j.1439-0329.2000.00191.x

23 Sieber TN, Hugentobler C, 1987. Endophytische Pilze in Blättern und Ästen 
gesunder und geschädigter Buchen (Fagus sylvatica L.). European Journal of Forest Pathology 17: 411-425.

3 Tamura K, Peterson D, Peterson N, Stecher G, Nei M, Kumar S, 2011. MEGA5:

4

5

6

8

9

10 11 Canadian Journal of Botany 51: 2275-2290; doi: 10.1139/b73-295. molecular evolutionary genetics analysis using maximum likelihood, evolutionary distance, and maximum parsimony methods. Molecular Biology and Evolution 28: 2731-2739; doi: 10.1093/molbev/msr121.

Vilgalys R, Hester M, 1990. Rapid genetic identification and mapping of enzymatically amplified ribosomal DNA from several Cryptococcus species. Journal of Bacteriology 172: 4238-4246.

Widden P, Parkinson D, 1973. Fungi from Canadian coniferous forest soils. 
$1 \quad$ Figure legends

2

3 Fig. 1 - A fruiting shoot of Fagus crenata.

4

$5 \quad$ Fig. 2 - Endophytic fungal assemblage dissimilarity among organs examined in

6 Jun (bold), Aug (italic), and Oct (gray), represented by nonmetric

7 multidimensional scaling (NMDS, stress=0.155). Ll, leaf lamina; Lp, leaf petiole;

8 Cp, cupule; Cs, cupule stalk; T0, current year twig; T1, first-year twig. The

9 compositional dissimilarity between samples was assessed with the Bray-Curtis 10 dissimilarity index.

11

12 Fig. 3 - Frequency (\%) of major fungal taxa on organs of fruiting shoots. Striped,

13 Jun; shaded, Aug; blank, Oct. Ll, leaf lamina; Lp, leaf petiole; Cp, cupule; Cs,

14 cupule stalk; T0, current year twig; T1, first-year twig. Results of generalized

15 linear models are indicated. ${ }^{* * *}, P<0.001$. The same letters are not significantly 16 different between organs at 5\% level with Tukey's test. 
1 Tateno et al. Fig. 1

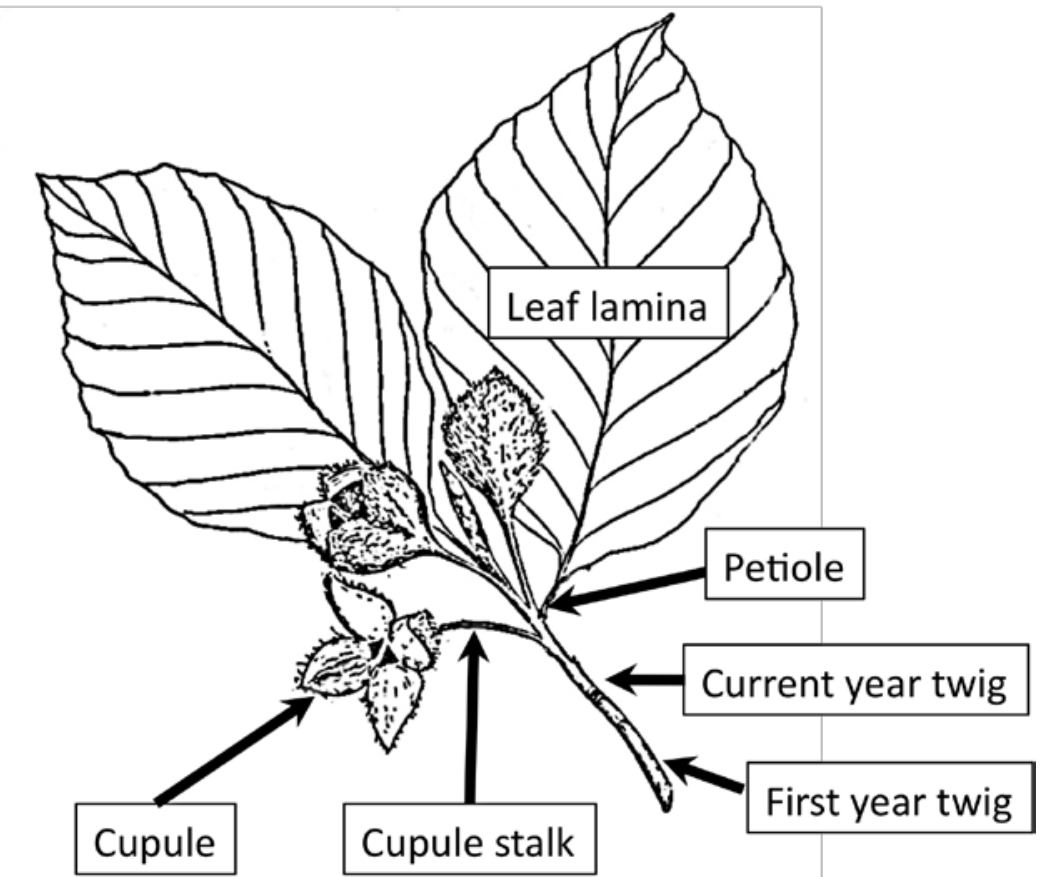


1 Tateno et al. Fig.2

2

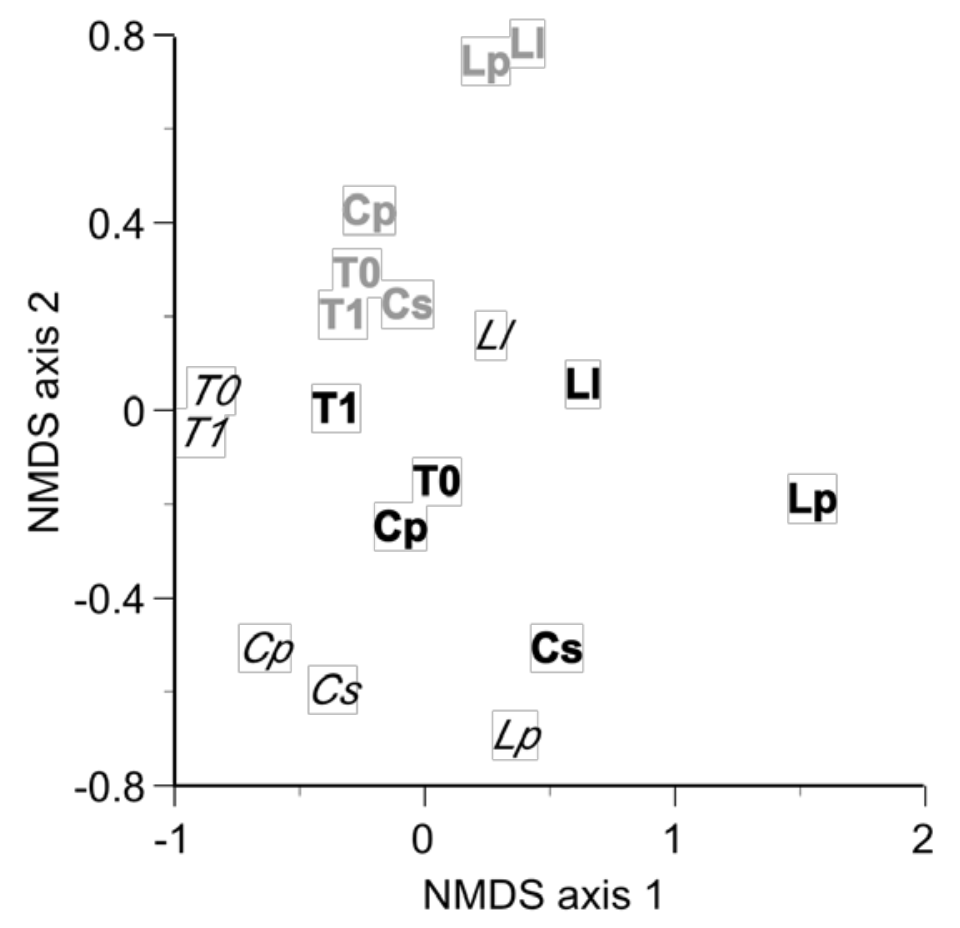


1 Tateno et al. Fig.3
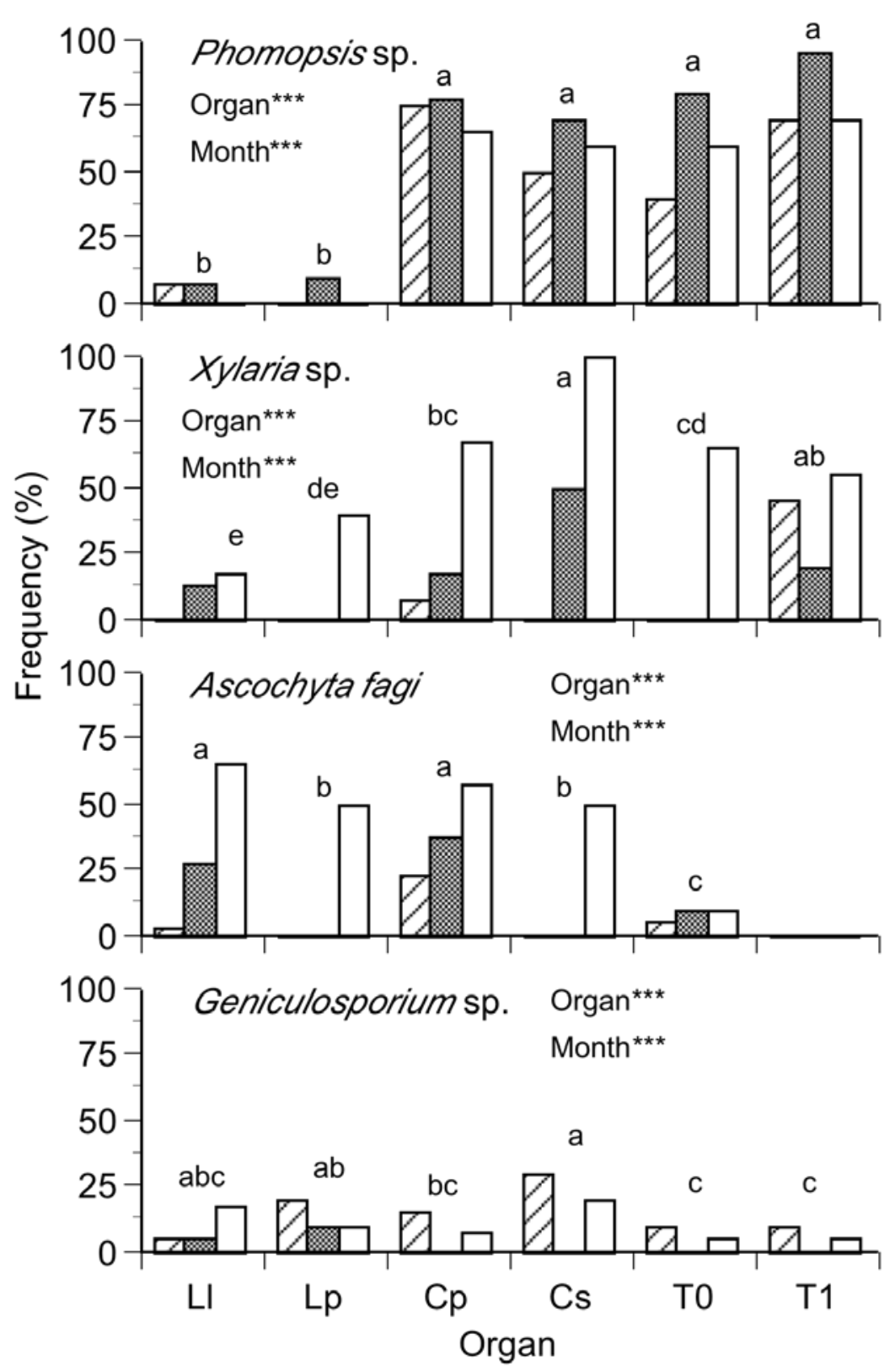